\title{
Peripapillary Choroidal Thickness Measurement in Glaucoma Patients Using Spectral Domain Optical Coherence Tomography
}

\author{
OSAMA A. RASLAN, M.D.; MOHAMED A. ZAKI, M.D.; TAMER F. ELIWA, M.D. and \\ IBRAHIM G. TAWFIK HELAL, M.Sc.
}

The Department of Ophthalmology, Faculty of Medicine, A in Shams University

\begin{abstract}
Background: Glaucoma, the leading cause of irreversible blindness worldwide, can adversely impact quality of life for patients with visual field defects even if they are unaware of their diagnosis. In many populations, POAG is the most common form of the disease.
\end{abstract}

Aim of Study: To measure peripapillary choroidal thickness in eyes with primary open angle glaucoma versus normal eyes using spectral-domain optical coherence tomography (SDOCT) with enhanced depth imaging mode (EDI).

Patients and Methods: The present study involved Ninety eight eyes of fifty adult patients were included in this observational, case control study. These cases were collected from out-patient ophthalmic clinic of Ain Shams University Hospital during the period from March, 2018 till March, 2019.

Results: A total 98 eyes of 50 patients were included in this observational study, with mean age of 52.26 years old. $48 \%$ of patients were males [24/50], while females were $52 \%$ [26/50]. These cases were divided into control group (50 eyes of 25 healthy controls) and glaucoma group (48 eyes of 25 patients).

Conclusion: Peripapillary choroidal thickness (PCT) in primary open angle glaucoma cases shows no significant correlation nor in early or sever cases, so PCT has no role in early detection or follow-up of primary open angle glaucoma cases.

Key Words: Primary open angle glaucoma-Peripapillary choroidal thickness - Optical coherence tomography-enhanced depth imaging mode.

\section{Introduction}

GLAUCOMA is the foremost cause of irreversible blindness, affecting more than 70 million people around the globe. Accumulating evidence reveals that glaucoma is a multifactorial neurodegenerative disease resulting from the loss of retinal ganglion cells (RGC) and from damage to the optic nerve $(\mathrm{ON})$. Both defects ultimately result in progressive permanent vision loss [1].

Correspondence to: Dr. : Ibrahim G. Tawfik Helal, E-Mail: dr.i.gamal@gmail.com
Elevated intraocular pressure (IOP) is the major risk factor for glaucoma, and its reduction can slow the progression of vision loss even in normal tension glaucoma (NTG) [2]. On the other hand, loss of visual function may continue even with medically or surgically controlled IOP, indicating that IOP-independent factors such as worsened choroidal blood flow parameters may play a role in ocular hypertension, NTG, or primary open angle glaucoma (POAG) [3]

Other studies have reported that patients experiencing glaucoma progression have worse ocular hemodynamics than nonprogressors $[4,5]$.

There has been increasing interest in investigating the role of the choroid in the pathogenesis of glaucomatous optic neuropathy (GON). Previous studies have found an association between GON and impaired choroidal circulation or blood flow to the optic nerve head (ONH) [5] . In addition, a limited number of studies, mostly histologic, have investigated the association between glaucoma and choroidal thickness with inconsistent findings [6]

Adequate visualization of the choroid using optical coherence tomography (OCT) has not been possible until recently, due to its posterior location and the presence of pigmented cells that attenuate the incident light.

The peripapillary choroidal thickness measured by enhanced depth imaging optical coherence tomography (EDI-OCT) were correlated with inconsistent results in both primary open angle and angle closure glaucoma [7-9].

In addition, it has been suggested that patients with normal tension glaucoma had significantly thinner peripapillary choroidal thickness compared to normal. Choroidal imaging by the EDI-OCT 
technique may serve as a tool to investigate the vascular theory of glaucoma pathogenesis [9].

Aim of the work:

The purpose of this study is to measure peripapillary choroidal thickness in eyes with primary open angle glaucoma versus normal eyes using spectral-domain optical coherence tomography (SD-OCT) with enhanced depth imaging mode (EDI).

\section{Patients and Methods}

The present study involved Ninety eight eyes of fifty adult patients were included in this observational, case control study. These cases were collected from out-patient ophthalmic clinic of Ain Shams University Hospital during the period from March, 2018 till March, 2019. These cases were divided into 2 groups:

- Group 1 (Control group): 50 eyes of 25 healthy person with no history of systemic and ocular diseases.

- Group 2 (Glaucoma group): 48 eyes of 25 patients previously diagnosed with POAG, controlled medically, with the following inclusion \& exclusion criteria.

\section{Inclusion criteria:}

For POAG patients: Eyes with:

1- Open angle (> grade 2).

2- Raised IOP without secondary causes $(>21 \mathrm{~mm}$ $\mathrm{Hg}$ ), were receiving IOP-lowering therapy.

3- Glaucomatous optic neuropathy (defined as a vertical cup/disc (C/D) ratio $>0.7$ and/or C/D asymmetry $>0.2$ and/or focal notching).

4- Visual field changes on static automated perimetry in the form of:

- Glaucoma hemifield test outside normal limits.

- Abnormal pattern and a SD of P value less than $5 \%$ in the healthy population.

- Fulfilling test reliability criteria (fixation losses $<20 \%$, false positives $<33 \%$, and/or false negatives $<33 \%$ ).

- For each POAG patient, a healthy subject was enrolled and served as a control with:

1- No prior history of eye disease other than cataract not affecting the OCT image quality.

2-No intraocular surgery.

3- IOP not exceeding $21 \mathrm{~mm} \mathrm{Hg}$.
Exclusion criteria:

- Age $<18$.

- Refractive error $>-6.00$ diopter (D) and +6.00 D.

- Astigmatism amplitude more than 3.00 D.

- Cases with retinal diseases (such as diabetic retinopathy, macular degeneration, optic neuritis)

- Ocular trauma

- Neuro-ophthalmological disease that might affect the interpretation of the visual field.

- Cases with media opacity (vitrous hemorrhage, significant cataract or corneal opacity) that interfere with fundus examamination and OCT interpretation.

- Recent eye surgery (within 2 months).

The corresponding consent form followed the tenets of the Declaration of Helsinki. A written informed consent was obtained from each participants before enrolment. All applicable institutional regulations concerning the ethical use of human volunteers were followed during this research.

\section{Methods:}

Complete ophthalmic, medical and family history were taken.

All cases underwent a complete ophthalmologic examination including:

- Non-cycloplegic refraction was determined using an auto refractometer (ARK-310; NIDEK, Aichi, Japan). Refraction data were converted to spherical equivalents (SE), which were calculated by the additions of spherical refractive error values (in diopters [D]) to one-half of the cylindrical refractive power.

- BCVA measurement by Snellen's visual acuity chart, then converted into Logarithm of Minimum Angle of Resolution (LogMAR) for statistical analysis according to following conversion Table (1).

Table (1): Conversion table for Snellen's visual acuity records to $\operatorname{LogMAR}$ equivalent [10]

\begin{tabular}{lccc}
\hline Snellen & LogMAR & Snellen & LogMAR \\
\hline $6 / 6$ & 0.00 & $6 / 48$ & 0.90 \\
$6 / 7.5$ & 0.10 & $6 / 60$ & 1.00 \\
$6 / 9.5$ & 0.20 & $6 / 90$ & 1.2 \\
$6 / 12$ & 0.30 & $6 / 120$ & 1.3 \\
$6 / 15$ & 0.40 & $6 / 150$ & 1.4 \\
$6 / 19$ & 0.50 & $6 / 180$ & 1.5 \\
$6 / 24$ & 0.60 & $6 / 240$ & 1.6 \\
$6 / 30$ & 0.70 & $6 / 360$ & 1.8 \\
$6 / 38$ & 0.80 & $6 / 480$ & 1.9 \\
\hline
\end{tabular}


- Slit lamp biomicroscopy of anterior segment.

- Stereoscopic fundus examination through fully dilated pupil using slit lamp biomicroscopy with +90D lens to detect glaucomatous optic disc changes [cupping, asymmetrical cupping difference $>0.2$, notching, kinking of vessels, NFL defects and peripapillary atrophy].

- IOP measurement by Goldmann applanation tonometer.

- Standard automated perimetry (SAP) with Humphrey Visual Field Analyser II (Carl Zeiss Meditec, Dublin, CA) was performed using the Swedish Interactive Thresholding algorithm (SITA) standard 24-2 test pattern. Pattern standard deviation (PSD), Mean Deviation (MD) and field defects were noted. The reliability criteria that were applied were as follows: false-positive and false-negative response rates were $20 \%$ or less or a reliability factor of less than $15 \%$. A VF defect was defined as one in which at least 3 adjacent points had at least a 5-dB loss, or at least 1 point had at least a $10-\mathrm{dB}$ loss, or a difference of at least $10 \mathrm{~dB}$ across the nasal horizontal meridian in 2 adjacent points in a compared numerical map. Any detected VF defect had to be confirmed.

- Optical Coherence Tomography Scanning with Spectralis SD OCT system (Heidelberg Engineering, Heidelberg, Germany) was performed using the built-in NFL circle scan protocol of $3.4 \mathrm{~mm}$ around optic disc with enhanced depth imaging technique. The OCT scans were excluded if the image quality was low. All study eyes were dilated with mydriatic eye drops before image acquisition. Patients were instructed to fixate on the intrinsic fixation target during the whole process of OCT scanning. If the patient was not fixating well and the center of image was not on center of the fovea, manual adjustment was performed. The OCT scans were performed by a single experienced doctor.

Determination of NFL thickness \& choroidal Thickness: The NFL thickness was automatically measured and analyzed in comparison to its normative database. The choroidal thickness was measured manually at the peripapillary area, in four quadrants (inferior, superior, nasal and temporal) starting from the outer portion of the hyperreflective line corresponding to the RPE to the inner surface of the sclera (choroid sclera interface). The choroid was measured by two independent graders who were blinded to the diagnosis, then their measurements were averaged. Fig. (1) shows EDI-OCT of left eye of a 36 years old female patient in this study showing peripapillary RNFL and choroidal thickness measurement in inferior, superior, nasal, temporal quadrants.

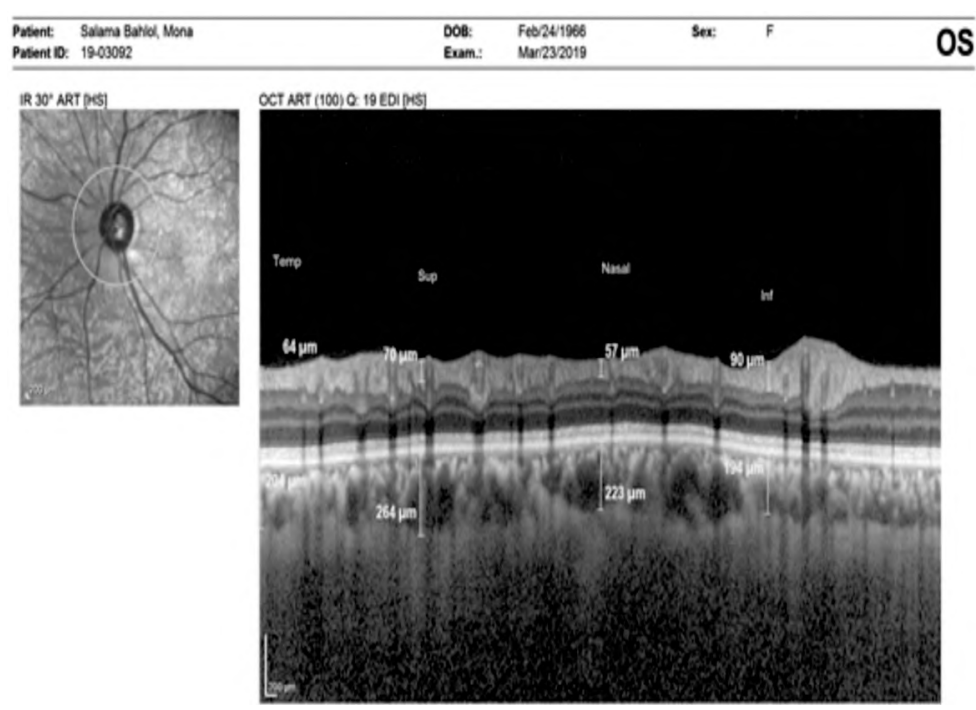

Fig. (1): EDI-OCT of left eye of a patient of this study.

\section{Statistical analysis:}

Data were collected, revised, coded and entered to the Statistical Package for Social Science (IBM SPSS) version 23 . The quantitative data were presented as mean, standard deviations and ranges when parametric. Also qualitative variables were presented as number and percentages.
The comparison between groups regarding qualitative data was done by using Chi-square test and/or Fisher exact test when the expected count in any cell found less than 5 .

The comparison between two groups regarding quantitative data and parametric distribution was 
done by using Independent $t$-test while with non parametric distribution was done by using MannWhitney test.

Spearman correlation coefficients were used to assess the correlation between two quantitative parameters in the same group.

The confidence interval was set to $95 \%$ and the margin of error accepted was set to $5 \%$. So, the pvalue was considered significant as the following: - $p$-value $>0.05$ : Non significant (NS).

- $p$-value <0.05: Significant (S).

- $p$-value <0.01: Highly significant (HS).

\section{Results}

The mean age of control group was $50.08 \pm 9.78$ years old versus $54.44 \pm 9.47$ years old in gluacoma group. Females were more in control group while males were more in glaucoma group. There is no statistically difference between them and patient's baseline demographics are shown in Table (2).

Table (2): Patient's demographics data of both groups.

\begin{tabular}{llll}
\hline & Control cases & Glaucoma cases & $\begin{array}{c}p \text { - } \\
\text { value }\end{array}$ \\
\cline { 1 - 3 } Age: & No. $=25$ & \multicolumn{1}{c}{ No. $=25$} & \\
$\quad$ Mean \pm SD & $50.08 \pm 9.78$ & $54.44 \pm 9.47$ & 0.115 \\
$\quad$ Range & $27-65$ & $37-67$ & \\
Sex: & & & \\
$\quad$ Females & $14(56.0 \%)$ & $12(48.0 \%)$ & 0.571 \\
$\quad$ Males & $11(44.0 \%)$ & $13(52.0 \%)$ & \\
\hline
\end{tabular}

-: Independent $t$-test. $\quad *$ : Chi $=$ Square test.

Ocular demographics:

The mean best-corrected visual acuity (BCVA) was $0.83 \pm 0.11$ in glaucoma group (approximately $6 / 9$ and $0.20 \operatorname{LogMAR})$, which was less than control group $(0.87 \pm 0.09$, approximately $6 / 6$ and 0.00 LogMAR). This difference was statistically non significant ( $p$-value 0.071) (Table 3).

Table (3): Patient's ocular demographics in control and glaucoma groups.

\begin{tabular}{llll}
\hline & Control cases & Glaucoma cases & $\begin{array}{c}p \text { - } \\
\text { value }\end{array}$ \\
\cline { 1 - 2 } & No. $=25$ & \multicolumn{1}{c}{ No. $=25$} & \\
\hline BCVA: & & & \\
$\quad$ Mean \pm SD & $0.87 \pm 0.09$ & $0.83 \pm 0.11$ & 0.071 \\
$\quad$ Range & $0.7-1$ & $0.6-1$ & \\
IOP: & & & \\
$\quad$ Females & $13.94 \pm 1.98$ & $17.89 \pm 1.35$ & 0.000 \\
$\quad$ Males & $10-18$ & $15-20$ & \\
\hline
\end{tabular}

$\bullet$ Independent $t$-test.

The mean NFL thickness of the all quadrants was less in glaucoma group than controls. These differences were statistically significant in all quadrants ( $p$-value $<0.05)$ (Table 4).
Table (4): The average NFL thickness in different quadrants in Controls \& glaucoma group.

\begin{tabular}{llll}
\hline $\begin{array}{l}\text { Nerve fiber } \\
\text { layer }\end{array}$ & Control cases & Glaucoma cases & $\begin{array}{c}p \text { - } \\
\text { value }\end{array}$ \\
\hline $\begin{array}{l}\text { Inferior: } \\
\quad \text { Mean } \pm \text { SD }\end{array}$ & $\begin{array}{l}102.32 \pm 19.66 \\
\quad\end{array}$ & $\begin{array}{l}89.73 \pm 21.81 \\
63-132\end{array}$ & 0.004 \\
$\quad$ Range & $70-142$ & & \\
Superior: & & $91.09 \pm 23.74$ & 0.001 \\
$\quad$ Mean \pm SD & $99.10 \pm 19.75$ & & \\
$\quad$ Range & $72-150$ & $55-150$ & \\
Nasal: & & & \\
$\quad$ Mean \pm SD & $62.38 \pm 10.68$ & $52.00 \pm 13.06$ & 0.000 \\
$\quad$ Range & $50-85$ & $42-62$ & \\
Temporal: & & & \\
$\quad$ Mean \pm SD & $63.70 \pm 7.34$ & $70.84 \pm 18.73$ & 0.014 \\
$\quad$ Range & $50-75$ & $46-140$ & \\
\hline
\end{tabular}

$\bullet$ Independent $t$-test.

The mean peripapillary Choroidal thickness in different quadrants was less in glaucoma than controls. These differences were statistically non significant in all quadrants ( $p$-value $>0.05$ ) (Table 5).

Table (5): The average peripapillary choroidal thickness in different quadrants in both controls \& glaucoma groups.

\begin{tabular}{|c|c|c|c|c|c|}
\hline $\begin{array}{l}\text { Choroidal } \\
\text { thickness }\end{array}$ & $\begin{array}{c}\text { Control } \\
\text { cases }\end{array}$ & $\begin{array}{l}\text { Glaucoma } \\
\text { cases }\end{array}$ & $\begin{array}{c}\text { Test } \\
\text { value }\end{array}$ & $\begin{array}{c}p- \\
\text { value }\end{array}$ & Sig. \\
\hline $\begin{array}{l}\text { Inferior: } \\
\text { Mean } \pm \mathrm{SD} \\
\text { Range }\end{array}$ & $\begin{array}{l}179.06 \pm 54.64 \\
67-308\end{array}$ & $\begin{array}{l}156.64 \pm 62.76 \\
67-276\end{array}$ & 1.861 & 0.066 & NS \\
\hline $\begin{array}{l}\text { Superior: } \\
\text { Mean } \pm \text { SD } \\
\text { Range }\end{array}$ & $\begin{array}{l}198.96 \pm 48.14 \\
120-320\end{array}$ & $\begin{array}{l}178.98 \pm 52.59 \\
81-276\end{array}$ & 1.934 & 0.056 & NS \\
\hline $\begin{array}{l}\text { Nasal: } \\
\quad \text { Mean } \pm \text { SD } \\
\text { Range }\end{array}$ & $\begin{array}{l}200.64 \pm 64.21 \\
99-328\end{array}$ & $\begin{array}{l}177.31 \pm 59.70 \\
83-289\end{array}$ & 1.828 & 0.071 & NS \\
\hline $\begin{array}{l}\text { Temporal: } \\
\text { Mean } \pm \text { SD } \\
\text { Range }\end{array}$ & $\begin{array}{l}182.84 \pm 41.25 \\
96-299\end{array}$ & $\begin{array}{l}167.62 \pm 61.76 \\
57-299\end{array}$ & 1.425 & 0.158 & NS \\
\hline
\end{tabular}

The average Mean deviation \& PSD in field sensitivity was higher in glaucoma groups than controls. This difference was statistically highly significant ( $p$-value <0.001) (Table 6).

Table (6): The average MD and PSD of both controls \& glaucoma groups.

\begin{tabular}{|c|c|c|c|}
\hline Visual field & Control cases & Glaucoma cases & $\begin{array}{c}p- \\
\text { value }\end{array}$ \\
\hline \multicolumn{4}{|l|}{$M D:$} \\
\hline $\begin{array}{l}\text { Mean } \pm \text { SD } \\
\text { Range }\end{array}$ & $\begin{array}{l}-0.53 \pm 0.61 \\
-1.01-0.98\end{array}$ & $\begin{array}{l}-6.01 \pm 3.30 \\
-12.03--1.4\end{array}$ & 0.000 \\
\hline \multicolumn{4}{|l|}{ PSD: } \\
\hline Mean \pm SD & $1.48 \pm 0.22$ & $6.76 \pm 3.80$ & 0.000 \\
\hline Range & $1.11-2.03$ & $1.3-13.66$ & \\
\hline
\end{tabular}

•: Mann-Whitney test. 
Case 1: 56 years old male with POAG, whose BCVA was 0.8 .

(A)
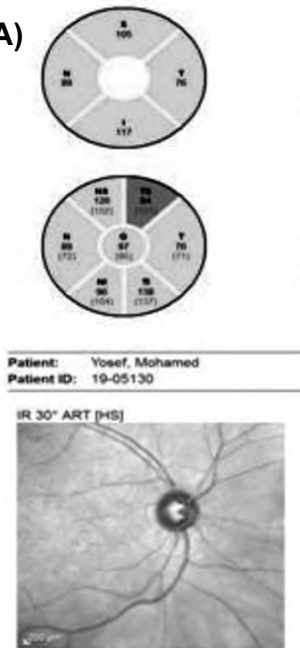

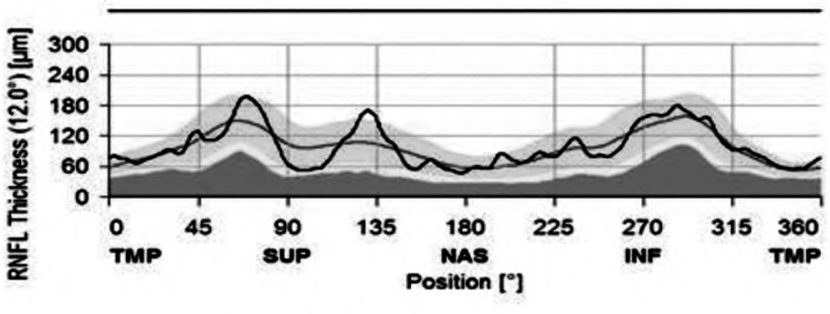

\begin{tabular}{l} 
Doe: \\
Exam: $\quad M a / 2511055$ \\
\hline
\end{tabular} OD

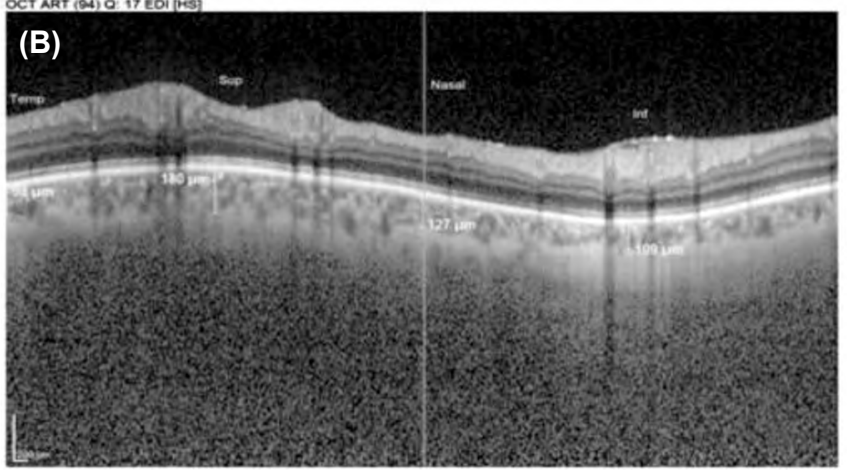

Fig. (2): OCT picture of right eye of case one. (A) Average RNFL; (B) peripapillary choridal thickness.

Table (7): Right eye OCT-ONH of case one shows thickness of RNFL and peripapillary choroid.

\begin{tabular}{lcccc}
\hline & Inferior & Superior & Nasal & Temporal \\
\hline RNFL & 126 & 118 & 73 & 78 \\
Peripapillary choroidal thickness & 109 & 180 & 127 & 98 \\
\hline
\end{tabular}

(A)
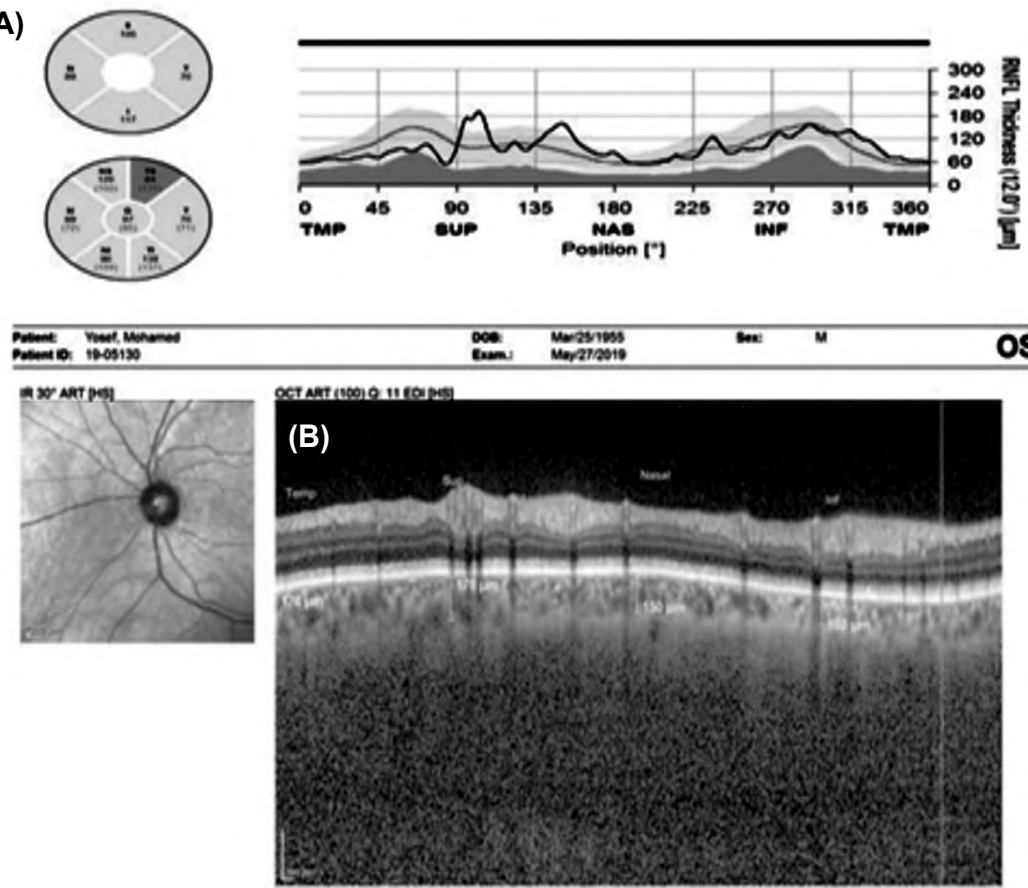

Fig. (3): Left OCT-ONH of case one with BCVA 0.8 shows; (A) Average RNFL thickness, (B) Peripapillary choroidal thickness. 
Table (8): Left eye OCT-ONH of case one shows thickness of RNFL and peripapillary choroid.

\begin{tabular}{lcccc}
\hline & Inferior & Superior & Nasal & Temporal \\
\hline RNFL & 117 & 105 & 89 & 76 \\
$\begin{array}{l}\text { Peripapillary } \\
\text { choroidal thickness }\end{array}$ & 102 & 170 & 150 & 178 \\
\hline
\end{tabular}

Table (9): Parameters of reliable visual field of case one shows outside normal limits.

\begin{tabular}{llll}
\hline GHT & PSD & MD & \\
\hline Outside normal limits & 4.75 & -7.75 & RT eye \\
Outside normal limits & 11.06 & -12.03 & LT eye \\
\hline
\end{tabular}

Parameters of reliable visual field of case one shows outside normal limits (Figs. 4,5).

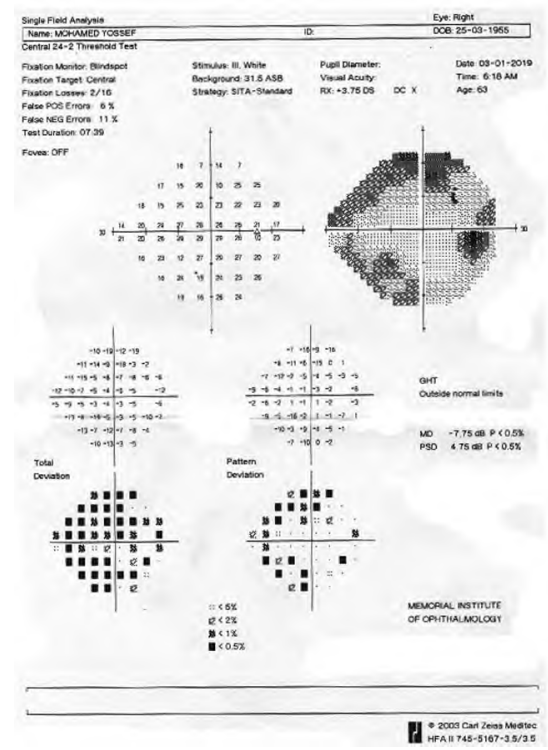

Fig. (4): Right visual field of case one.

\section{Discussion}

The role of the choroid among the complex network of factors involved in the pathogenesis of GON is incompletely understood. To contribute to the understanding of the relationship between the choroid and glaucoma, various studies have been carried out to measure the thickness of the choroid in glaucomatous eyes using histopathologic or in vivo imaging techniques.

The conflicting results of those studies, coupled with recent advances in imaging of the ocular posterior segment, particularly the SD-OCT, were the motive for reassessing the relationship between choroidal thickness and glaucoma.

\section{According to our study:}

Peripapillary choroidal thickness in glaucoma group was lass than control group, but this difference was statistically insignificant with $p$-value (0.066-0.056-0.071-0.158) in (inferior-superiornasal-temporal) quadrants respectively.

Also, there was non significant correlation between average NFL and peripapillary choroidal thickness in all quadrants except for the nasal quadrant which shows significant positive correla-

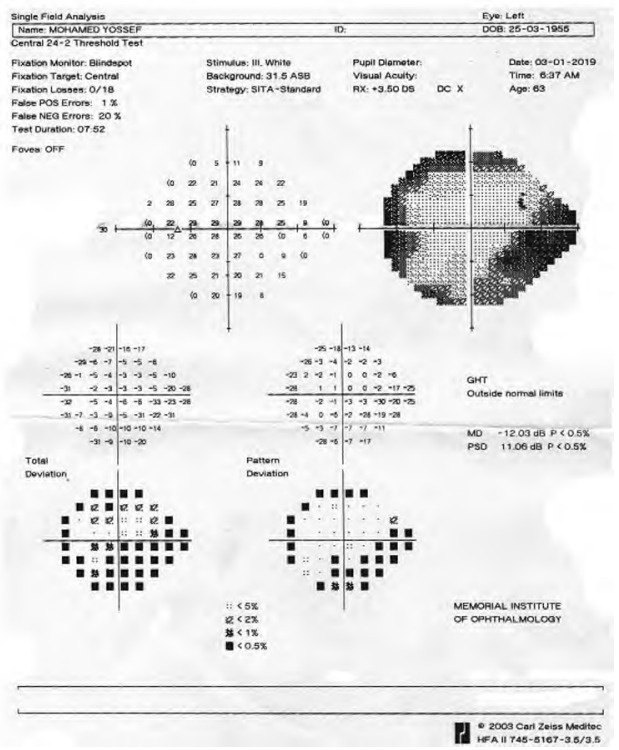

Fig. (5): Left visual field of case one.

tion with correlation coefficient $0.297, p$-value 0.003 ).

There was non significant correlation between MD of visual field and peripapillary choroidal thickness in all quadrants.

This study shows mild inverse correlation between peripapillary choroidal thickness and PSD in superior and nasal quadrants with $p$-value $(0.023$, $0.011)$ respectively.

The main finding of our study is thicker peripapillary choroid in normal than POAG, but this difference was not statistically significant ( $p$-values $=0.7$ ).

So our study results support the findings from previous studies on peripapillary choroidal thickness and glaucoma:

Ehrlich et al. [11] assessed circumpapillary choroidal thickness with Spectralis SD-OCT in a retrospective study and concluded that eyes with primary open angle glaucoma did not demonstrate reduced choroidal thickness nor was there a correlation between RNFL thickness and choroidal thickness in corresponding quadrants. In contrast to our results where we found insignificant reduc- 
tion of peripapillary CT in glaucoma group with a significant correlation between the average NFL thickness in nasal quadrant and peripapillary choroidal thickness in nasal quadrant (correlation coefficient of $0.3, p$-value $=0.003$ ).

Maul et al. [12] measured choroidal thickness with enhanced depth SD-OCT imaging in a group of glaucoma suspects and glaucoma patients, and they found that the severity of glaucomatous damage was not found to be associated with choroidal thickness.

Meta-analyses conducted by Zhang et al. [13] both demonstrated no correlation between peripapillary choroidal thickness and POAG.

Mwanza et al. [7] reported their experience with in vivo imaging of the choroid with Spectralis SDOCT in primary open-angle and normal-tension glaucoma and normal control subjects. They confirmed that choroidal thickness was mainly influenced by age and axial length (thinner choroid with older age and longer axial length). However, the authors did not find any significant difference among the three groups with respect to choroidal thickness. In another study by the same author in 2012 on patients with unilateral advanced glaucoma, the same findings were confirmed, suggesting a lack of association not only between choroidal thickness and glaucoma but also with glaucoma severity.

In 2014, Hosseini and colleagues presented a study on macular and peripapillary choroidal thickness in patients with perimetric glaucoma. They did not find any significant difference in subfoveal choroidal thickness between patients with open angle glaucoma and non-glaucomatous individuals. They extended the examinations into the peripapillary region in which, except for the temporal region, choroidal thickness did not differ between glaucomatous and control eyes which close to the present results. These findings may imply that choroidal blood circulation may not be markedly involved or affected in open angle glaucoma. However, the choroid is a highly dynamic vascular tissue and purely anatomic measurements, such as choroidal thickness, may not adequately describe altered hemodynamic physiology in various ocular diseases. Specifically, flow patterns in the peripapillary choroid would be of great interest in glaucoma.

Arora et al. [14] found that the severity of glaucomatous optic nerve damage as measured by cup/disc ratio or visual field mean deviation was not significantly associated with choroidal thick- ness. Similarly, Hosseini et al. [15] and Mwanza et al. [16] observed that glaucoma severity (in terms of RNFL thickness and MD) was not associated with choroidal thickness. These findings are consistent with the current results as regards the correlation between $\mathrm{CT}$ and MD but not with PSD where there was inverse correlation between CT \& PSD.

The findings by the above-mentioned studies are consistent with results of this study regarding the lack of a significant difference between the peripapillary choroidal thickness in POAG and normal eyes.

\section{In comparison with our study:}

Bron et al. [8] reported thinner peripapillary choroidal thickness in POAG patients than normal controls in a study which involved 65 healthy eyes and 78 eyes with POAG. Also, another metaanalysis conducted by Lin et al. [17] demonstrated that average peripapillary choroidal thickness in open-angle glaucoma was significantly reduced compared to healthy individuals which was a potential support of the vascular theory of glaucoma and suggested that retrobulbar ischemia might have an impact on the optic nerve head. The difference between these results and that of the present study may be attributed to the relatively smaller sample size.

Regarding NTG, Hirooka et al. [9] demonstrated that the mean peripapillary choroidal thickness was significantly thinner in the NTG eyes when compared to normal subjects. In addition, they found that in the NTG patients, the peripapillary choroidal thickness of the inferonasal, inferior, or inferotemporal regions decreased in conjunction with a corresponding worsening of the visual hemifield defect but we found correlation between nasal peripallary CT and severity of visual field. In another study by Hirooka et al. [9], the choroidal thickness at $3 \mathrm{~mm}$ nasal from the fovea was significantly thinner in NTG eyes as compared to normal subjects and also correlated with the mean deviation slope.

The findings by Hirooka et al. [9] that the choroid was thinner in NTG than normal whereas in POAG was not increased or decreased when compared to normal may imply that abnormal choroidal blood supply may be one factor responsible for the occurrence of GON in NTG patients more than in POAG patients.

\section{Possible limitations of this study:}

- A cross-sectional study cannot show long term changes. 
- The relatively small sample size.

- Peripapillary choroidal thickness was only measured without measuring the subfoveal choroidal thickness.

\section{Conclusion:}

Peripapillary choroidal thickness (PCT) in primary open angle glaucoma cases shows no significant correlation nor in early or sever cases, so PCT has no role in early detection or follow-up of primary open angle glaucoma cases.

\section{References}

1- JIA X., YU J., LIAO S. and DUAN X.: Biomechanics of the sclera and effects on intraocular pressure. Int. J. Ophthalmol., 9 (12): 1824-1831, 2016.

2- HEIJL A., LESKE M., BENGTSSON B., et al.: 'Reduction of intraocular pressure and glaucoma progression: Results from the Early Manifest Glaucoma Trial', Arch. Ophthalmol., 120: 1268-1279, 2002.

3- FUCHSJAGER-MAYRL G., WALLY B., GEORGOPOULOS M., et al.: 'Ocular blood flow and systemic blood pressure in patients with primary open-angle glaucoma and ocular hypertension', Invest Ophthalmol. Vis. Sci., 45: 834-839, 2004.

4- SATILMIS M., ORGUL S., DOUBLER B., et al.: ' Rate of progression of glaucoma correlates with retrobulbar circulation and intraocular pressure', Am. J. Ophthalmol., 135: 664-669, 2003.

5- GALASSI F., SODI A., UCCI F., et al.: 'Ocular hemodynamics and glaucoma prognosis: A color Doppler imaging study', Arch. Ophthalmol., 121: 1711-1715, 2003.

6- SPRAUL C., LANG G., LANG G., et al.: 'Morphometric changes of the choriocapillaris and the choroidal vasculature in eyes with advanced glaucomatous changes', Vision Res., 42: 923-932, 2002.

7- MWANZA J., HOCHBERG J., BANITT M., et al.: 'Lack of Association between Glaucoma and Macular Choroidal
Thickness Measured with Enhanced Depth-Imaging Optical Coherence Tomography', Invest. Ophthalmol. Vis. Sci., 52 (6): 3430-3435, 2011.

8- BRON A., FRANCOZ A., BEYNAT J., et al.: 'Is choroidal thickness different between glaucoma patients and healthy subjects?', Acta. Ophthalmologica, 89: 1755-1768, 2011.

9- HIROOKA K., FUJIWARA A., SHIRAGAMI T., et al.: 'Relationship between progression of visual field damage and choroidal thickness in eyes with normal-tension glaucoma', Clin. Exp. Ophthalmol., 40 (6): 576-582, 2012.

10- RICE J. and STEFFEN J.: Outcomes of vitrectomy for advanced diabetic retinopathy at Groote Schuur Hospital, Cape Town, South Africa. SAMJ S. Afr. Med. J., 105 (6), 2015.

11-EHRLICH J., PETERSON J., PARLITSIS G., KAY K.Y., KISS S. and RADCLIFFE N.: Peripapillary choroidal thickness in glaucoma measured with optical coherence tomography. Exp. Eye Res., 92 (3): 189-194, 2011.

12- MAUL E., FRIEDMAN D., CHANG D., et al.: 'Choroidal thickness measured by spectral domain optical coherence tomography: Factors affecting thickness in glaucoma patients', Ophthalmology, 118: 1571-1579, 2011.

13-ZHANG C., TATHAM A., MEDEIROS F., et al.: 'Assessment of Choroidal Thickness in Healthy and Glaucomatous Eyes Using Swept Source Optical Coherence Tomography', PLOS ONE, 9, 2014.

14- ARORA K., JEFFERYS J., MAUL E., et al.: 'The choroid is thicker in angle closure than in open angle and control eyes', Invest Ophthalmol. Vis. Sci., 53: 7813-7818, 2012.

15- HOSSEINI H., NILFORUSHAN N., MOGHIMI S., et al.: 'Peripapillary and macular choroidal thickness in glaucoma', J. Ophthalmic. Vis. Res., 9: 154-161, 2014.

16-MWANZA J., DURBIN M., BUDENZ D., et al.: Glaucoma diagnostic accuracy of ganglion cell-inner plexiform layer thickness: Comparison with nerve fiber layer and optic nerve head. Ophthalmology, 119: 1151-1158, 2012.

17-LIN Z., HUANG S., XIE B., et al.: 'Peripapillary Choroidal Thickness and Open-Angle Glaucoma: A Meta-Analysis', Journal of Ophthalmology, p. 12, 2016. 


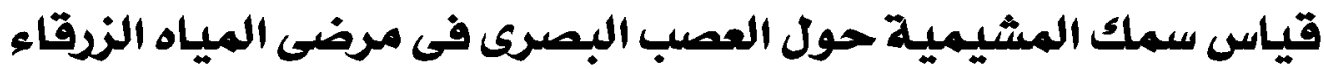

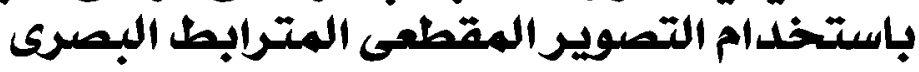

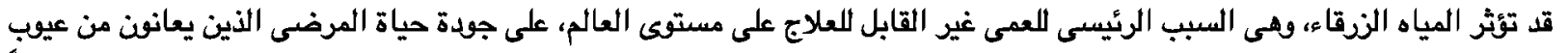

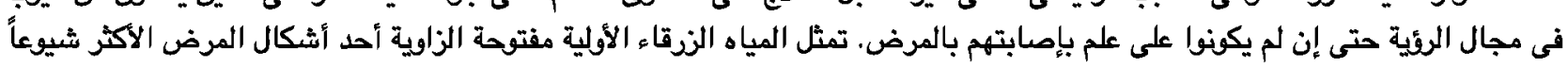
في معظم المجتمعات السكانية.

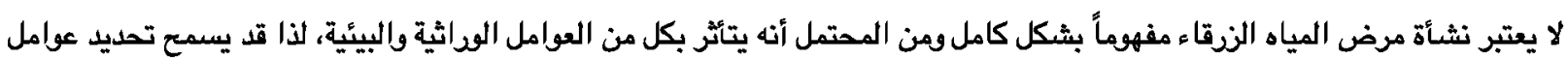

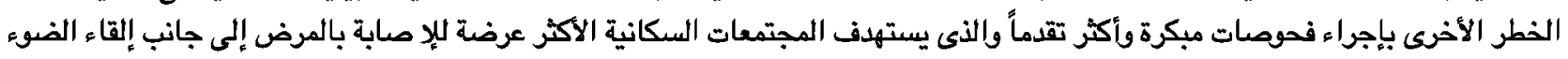
على الفيسيولوجيا المرضية لهذا المرض. لهرض.

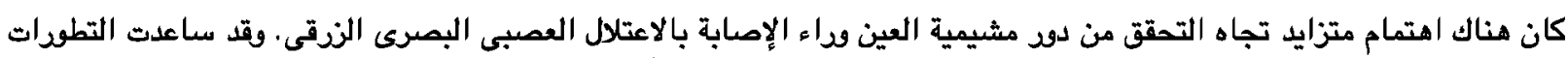

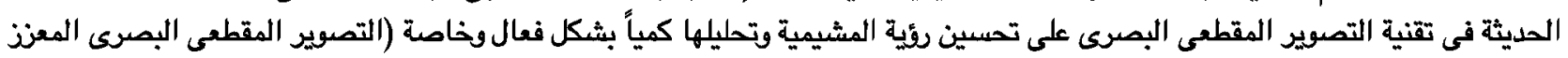
بعمق الصودة) والذى يؤدى إلى تصسين القدرة على رئية وقياس سمك المشيمية في الجسم الحئ. تتمثل النتيجة الرئيسية لدراستنا فى أن المشيمية حل العصب البصرى أكثر سمكاً فى أفراد حالات الأصحاء المقارنة في العمر ويتسمون

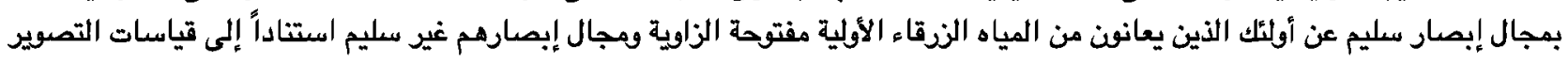
المقطعى البصرى المعزن بعمق الصودة لكن لم يتم التوصل إلى أن هذا الاختلاف ذو دلالة إحصائية (قيمة الدلالة الإحصائية =V . ..).

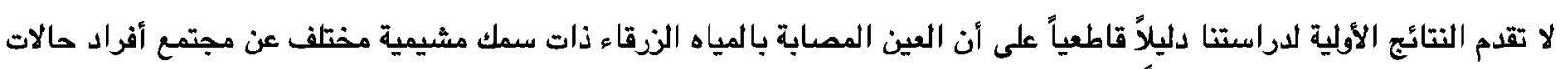

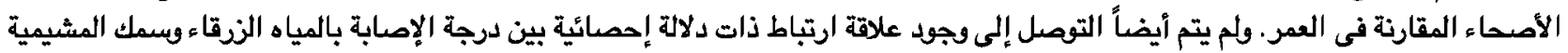

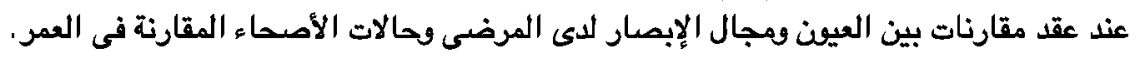

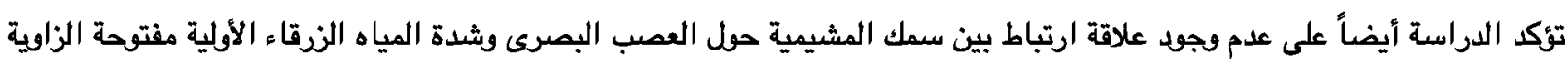

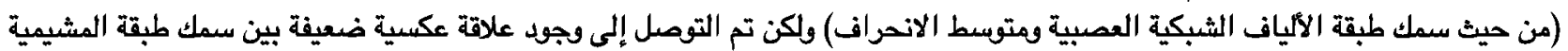

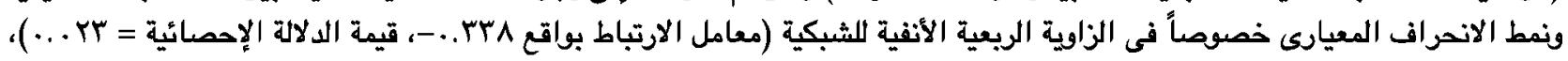

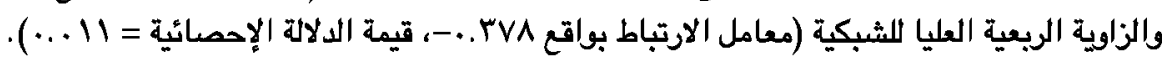

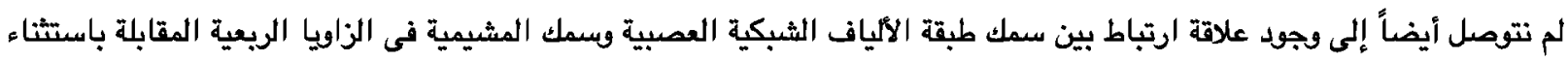

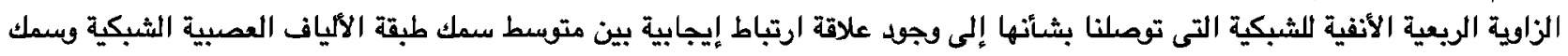

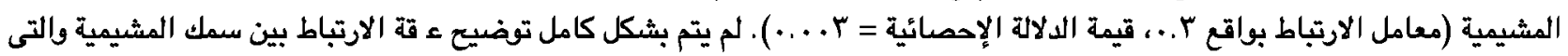

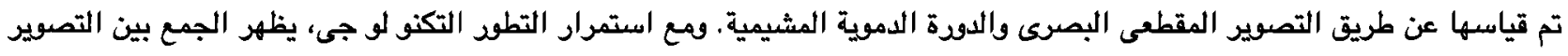

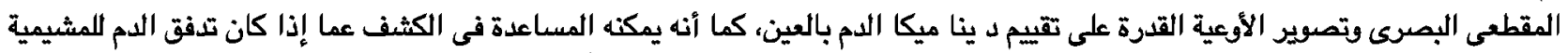

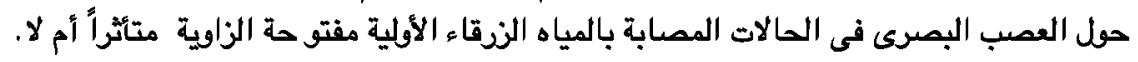

